\title{
EXPERIMENTAL STUDY OF ROUGHNESS EFFECTS ON TURBULENT BOUNDARY LAYER FLOW OVER A TWO-DIMENSIONAL HILL
}

\author{
Mohamed F. Yassin \\ Faculty of Engineering, Assiut University, Assiut-71516, Egypt \\ E-mail: mfy_64@yahoo.com
}

(Received July 12, 2006 Accepted July 27, 2006)

\begin{abstract}
Wind tunnel experiments were carried out to study the effects of surface roughness on a turbulent boundary layer over a twodimensional hill under neutral conditions by using a hot wire Constant Temperature Anemometer (CTA) system with a split-fibre probe. Rough surface conditions were modeled by placing two types of windbreak fence on the hill surface. Its porosities $\phi$ are $0 \%$ and 50\%. Measurements analysis includes mean velocity, turbulent velocity, Reynolds stress, turbulent energy and eddy viscosity profiles over the hill surface and in the wake region. The results obtained indicate the following: a) the mean velocity profiles for the types of windbreak fence slightly changes with the different fence arrangements, $b$ ) the turbulent velocity shows an almost uniform distribution across the windward ascent slope, $c$ ) the turbulence velocity becomes higher at the upper wake region behind the hill, $d)$ the porous fences work as strong windbreaks and weaken the wind velocity near the hill surface. This study can help to improve the database for validating the CFD method for predicting wind over a local terrain
\end{abstract}

KEYWORDS: Boundary layer; Hill; Mean flow; Roughness; Split fibre measurements.

\section{INTRODUCTION}

The detailed knowledge of the atmospheric flow around hills is of great interest in many engineering applications, particularly when dealing with wind loading and power mapping, pollution dispersion and agro-meteorological studies.

The majority of past studies on airflow over a hill have focused on these two flow features [1-3]. Meanwhile, it has been shown that the condition of the hill surface, smooth or rough, should be considered when studying the effects of topography on the airflow. Neff and Meroney [4] investigated the vegetation influence on wind power availability in terms of the amplification of wind speed on a crest with and without vegetation on its surface. They showed that removal of vegetation leads to an increase in the speed-up ratio on the crest. Miller and Davenport [5] examined the current Canadian and UK wind loading codes of practice for predicting speed-up on the crests 
of complex terrain considering the upstream surrounding topography and surface roughness. They implied the necessity of considering surface roughness and upstream flow conditions when predicting speed-up. Both these two studies were restricted to the speed-up ratio on the crest of a hill for their practical projects.

Several investigators have reported measurements of mean flow and turbulence in disturbed boundary layer over two-dimensional hills in wind tunnels. Plate \& Lin [6] have measured profiles of mean velocity and variance of longitudinal velocity fluctuations to large distances relative to the ridge height behind several types of 2-D ridge. Counihan et al. [7] have measured profiles of mean velocity, variance of longitudinal velocity fluctuations, variance of vertical velocity fluctuations and Reynolds stress in both the disturbed and undisturbed boundary layers developing in a comparatively small wind tunnel. Huber et al. [8] have reported wind tunnel measurements of mean flow and longitudinal turbulent intensity in a thick boundary layer disturbed by 2-D triangular and Gaussian ridges. Castro [9] has reported detailed measurements in wakes behind 2-D square blocks, which should be comparable to others. In recent years considerable attention has been focused on characteristics of the turbulent boundary layer over complex terrain that are covered by Taylor et al. [10], Ishihara \& Hibi [11] Almeida et al [12], Sierputowski et al [13], Meng \& Hibi [14] and Ishihara et al [15].

In addition, previous studies have shown that the instantaneous and mean flow behind a solid windbreak fence have different behavior. Fang \& Yang [16] have simulated the turbulent flow around a vertical porous fence by using a weakly compressible flow computational method. By varying the approaching flow condition and the porosity of the fence, the wake characteristics behind the fence are investigated. Shiau [17, 18] have reported measurements and analysis of the turbulence characteristics for a turbulent boundary layer flow past porous windscreen and over windbreak of semi-circular section. Packwood [19] has presented the results of a comparison wind tunnel tests and CFD modeling for flow downstream of a twodimensional porous fence in a thick boundary layer.

However, there is a limited amount of data available that would enable us to understand the effects of the surface roughness on the flow.

Mean flow and turbulence measurements in the wind tunnel were conducted with a hot wire Constant Temperature Anemometer (CTA) and split-fibre probes to measure three velocity components in order to provide details of the turbulence characteristics of flow over a two-dimensional hill with a rough surface. The results of wind tunnel measurements on the flow over two-dimensional hill with different porous fences, $\phi=$ 0,50 and $100 \%$ are reported in this paper. The purpose of this paper is to investigate the effects of roughness, porosity of obstacles and streamline curvature in a turbulent boundary layer over two-dimensional hill in order to get the database for validating the CFD method for predicting wind over a local terrain.

\section{WIND TUNNEL}

The experiments were conducted in $2.2 \mathrm{~m}$ wide, $1.8 \mathrm{~m}$ high and $17 \mathrm{~m}$ long test section of the wind tunnel. The schematic diagram of the wind tunnel experimental is illustrated in Fig. 1. The free stream velocity in the working section ranges from 1 to $33 \mathrm{~m} / \mathrm{s}$. A neutral stratified atmospheric boundary layer was simulated, using three 
spires, one $90 \mathrm{~mm}$ high cubic array placed just downstream of the contraction exit and followed by 60 and $30 \mathrm{~mm}$ cubic roughness element, covering $10.2 \mathrm{~m}$ of the testsection floor. This arrangement was employed to generate a thick turbulent boundary layer as the approaching flow. The mean velocity variation in the plane normal to the wind direction just after the contract section is less than $1 \%$. The turbulence intensity just after the contract section is less than $0.5 \%$.

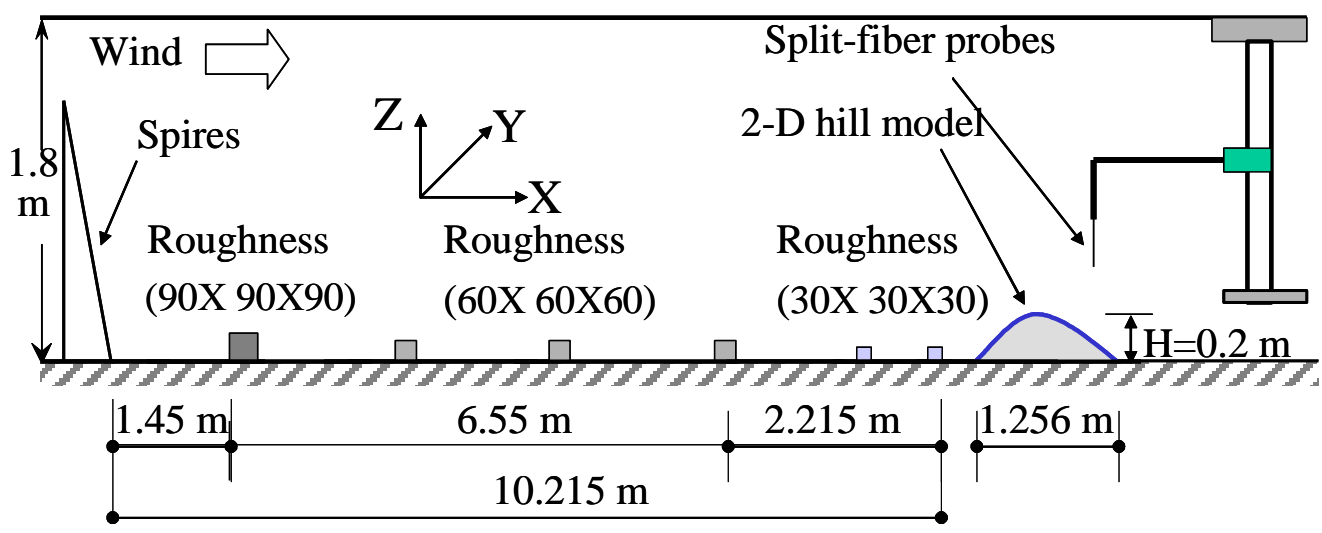

Fig. 1 Schematic diagram of the wind tunnel experimental.

\section{OUTLINE OF MODEL EXPERIMENT}

\subsection{Simulated Boundary Layer}

A thick turbulent boundary layer was simulated by positioning spires and arranging roughness blocks for a distance of $10.2 \mathrm{~m}$ from just after the contract section [20]. The mean velocity profile is correctly expressed by the power law.

$$
U \infty Z^{n}
$$

Where $\mathrm{U}$ is the mean velocity in the leeward direction; $\mathrm{Z}$ is the height above the ground, and $n$ is the power exponent. The typical value of $1 / 7$ for the power number $n$ in the present study was employed. A turbulent boundary layer for neutral atmospheric conditions in a rural area was simulated on a scale of 1/1000. Figure 2 shows the simulated turbulent boundary layer profile at $\mathrm{X}=-800 \mathrm{~mm}(\mathrm{X}=$ zero corresponds to the center of the hill model).

\subsection{Terrain Model}

A two-dimensional hill was used for the terrain model shown in Fig. 3. It is $200 \mathrm{~m}$ high $(H)$ and $1,256 \mathrm{~m}$ long $(L)$ at full scale. The shape of the hill is described by $Z=H(1-\cos (2 \pi X / L)$. A $1 / 1000$ scale model $(H=200 \mathrm{~mm})$ was used in the wind tunnel experiment. A photograph of the two-dimensional model with a rough surface in wind tunnel is shown in Fig. 4. 


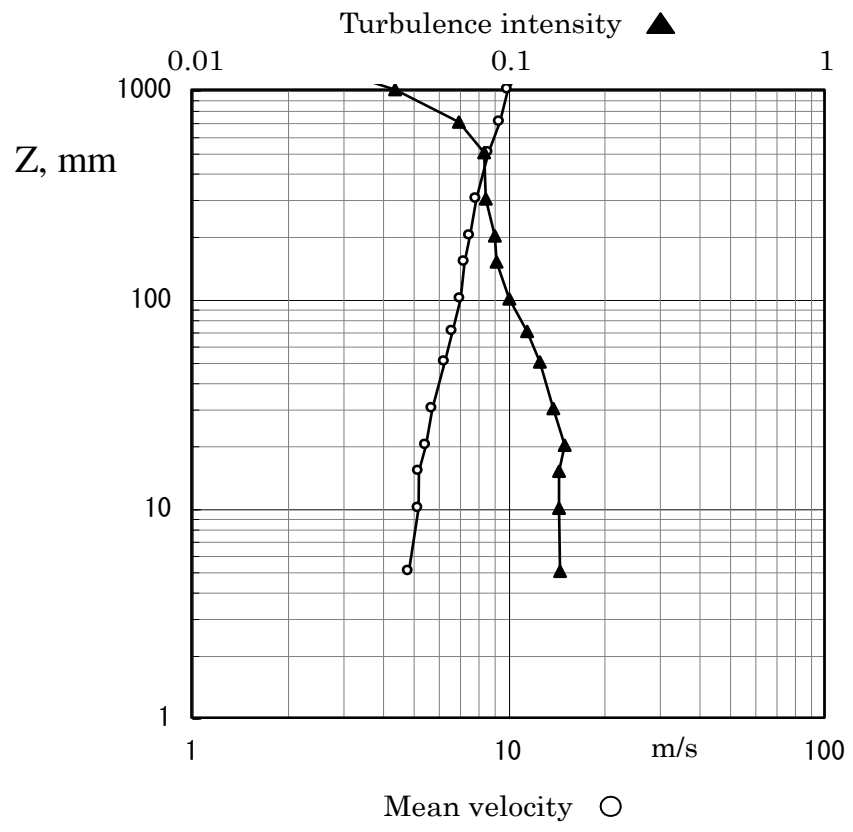

Fig. 2: Vertical distribution of mean velocity and turbulence intensity of incident flow (at $\mathrm{X}=-800 \mathrm{~mm} \mathrm{Y}=0$ ).

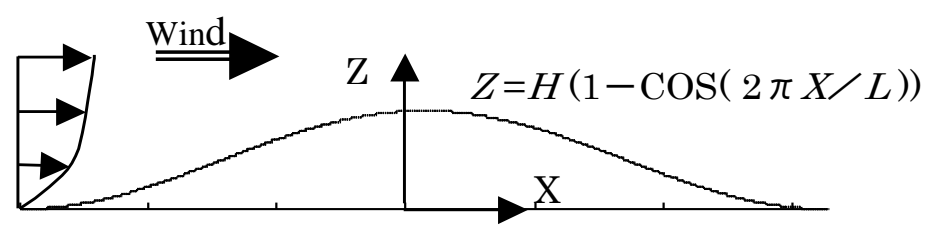

Fig. 3: Two-dimensional hill model

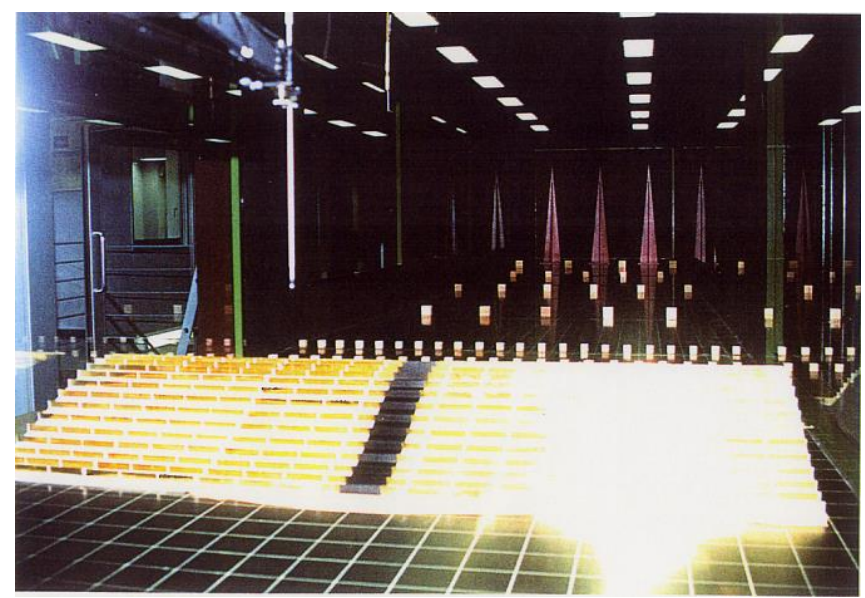

Fig. 4: Two-dimensional hill model with a rough surface. 
Tripping wires ( $1 \mathrm{~mm}$ rectangular columns, $50 \mathrm{~mm}$ intervals) are arranged on the surface. Two types of windbreak fence are positioned on the hill surface. They represent models for trees on the hill. All the fences are $20 \mathrm{~mm}$ high. One type is a solid plate fence and its porosity, $\phi$ is $0 \%$, which is shown in Fig. 5a. The other type is a fence made of punched metal plate and its porosity, $\phi$ is $50 \%$, which is shown in Fig. 5b. In the case without fences, we set the porosity of the fence at $100 \%$. The fences are positioned at intervals of $50 \mathrm{~mm}$, the same as for the tripping wires.

The terrain model is a little bit larger than the wind tunnel section. The blockage is $11 \%$. This should be taken into account when the measured characteristics are analyzed; however, one of the major purposes of the experiment is to obtain the data, which should be compared with the CFD simulation.
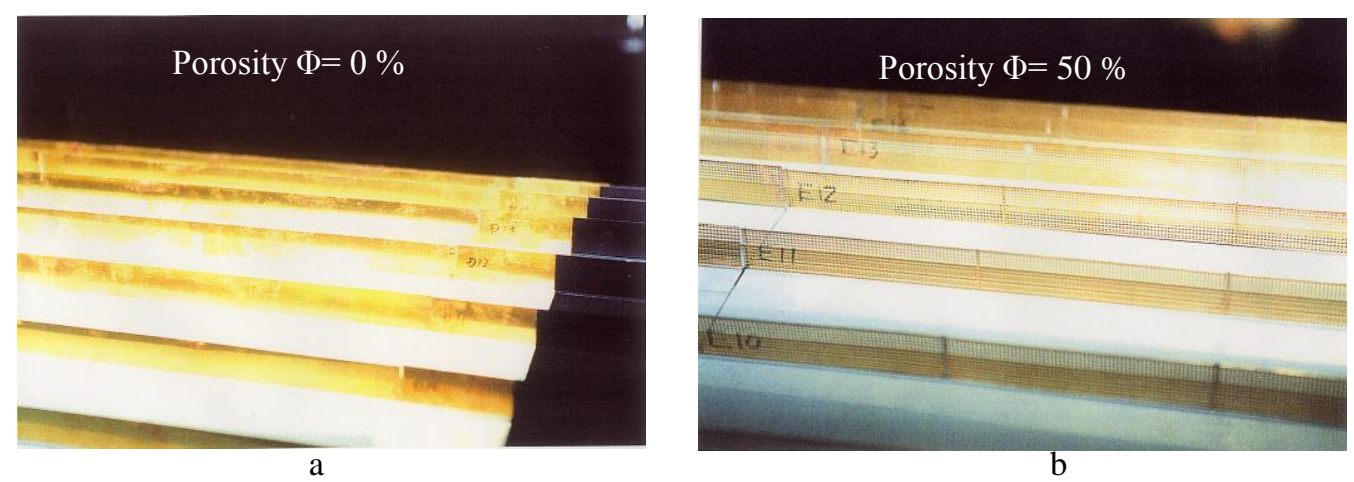

Fig. 5: Two types of windbreak fence.

\subsection{Flow Measurement}

Since X-wire probe anemometers for turbulence measurement cannot give reasonable accuracy when the turbulence intensity is larger than 0.3 [15], all velocity measurements over the hill were made with split-fibre probe (55R55) in conjunction with a 90N10 DANTEC constant temperature anemometer system. The probes were placed with respect to fixed Cartesian coordinates in the tunnel. The working principle of the split-fibre probes was the variation of the local transfer coefficient with flow angle for a heated cylinder placed in a cross flow. Accordingly, the sum of the heat transfer from the two sensors depended only on the velocity, while the difference depended on both velocity and flow angle in the plane perpendicular to the two sensors. The calibration procedure of the split-fiber probe has been described by Boerner and Leutheusser [21] and modified by Ishihara et al. [15]. In this study, the split-fiber probe 55R55 was calibrated using Ishihara et al.'s modified method. The calibration results showed that the deviation of the sum of the output voltages of the two separate sensors with pitch angle was lower than $71.5 \%$ within the velocity region of $1.0-8.0 \mathrm{~m} / \mathrm{s}$, while the difference between them, which implies the directional response of the probe, was favorably close to the ideal cosine function. The thin nickel films of the split-fiber probe, which are covered with $0.5 \mathrm{~mm}$ thick quartz coating to protect them against oxidation, were deposited on a $200 \mathrm{~mm}$ quartz fiber with an active length of $1.2 \mathrm{~mm}$. It 
was much larger than a standard wire/film probe, so its frequency response should be checked before being utilized to measure turbulence.

The anemometer signals were digitized at a sampling rate of $1 \mathrm{kHz}$ giving a total of 32768 samples. An X-type probe was used to measure the Reynolds stress.

\subsection{Two Dimensionality}

Figure 6 shows the vertical distribution of the mean velocity at three positions in the lateral direction (Y) along the top of the hill. It shows the degree of two-dimensionality. The deviation among in the three profiles is less than $2.4 \%$.

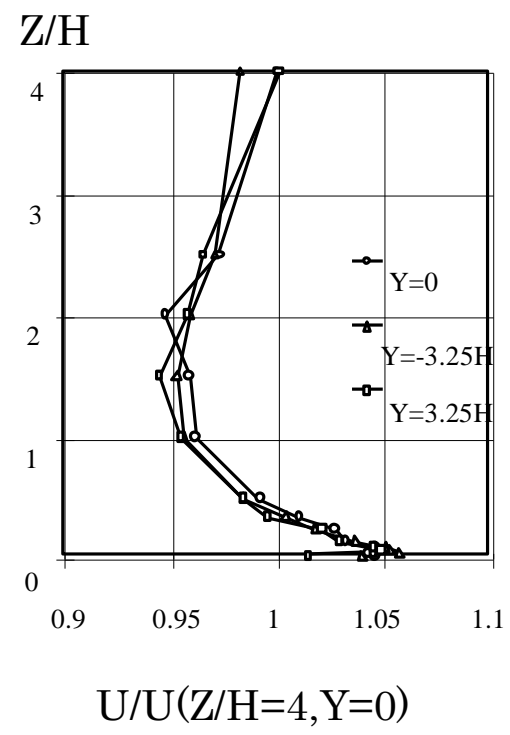

Fig. 6: Mean velocity distribution at different positions on top of the hill.

\section{RESULTS AND DISCUSION}

Three velocity components were measured at different lines from $\mathrm{A}$ to $\mathrm{K}$ along the central line of the hill model for three cases; that is, without a fence $(\phi=100 \%)$, with the solid fence $(\phi=0 \%)$. and with the porous fence $(\phi=50 \%)$. Some of the measured profiles have been omitted for clarity. The mean velocity and turbulent velocity distributions in the vertical direction over the hill are shown in Figs. 7 to 11. The mean velocity components are normalized by the reference velocity, $\mathrm{U}_{\mathrm{H}}$ which is the incident velocity at the top of the hill $(\mathrm{H}=200 \mathrm{~mm})$.

The mean velocity profiles for the three cases slightly change with the different fence arrangements. The peak wind speed $\left(\mathrm{U} / \mathrm{U}_{\mathrm{H}}\right)$ above the hill surface is 1.37 at line $\mathrm{C}, \mathrm{Z} / \mathrm{H}=0.05$ when $\phi=100 \%$ (without a fence), 1.33 at Line $\mathrm{E}, \mathrm{Z} / \mathrm{H}=0.625$ when $\phi$ $=0 \%$ (with the solid fence); and 1.47 at line $\mathrm{E}, \mathrm{Z} / \mathrm{H}=0.5$ when $\phi=50 \%$ (with the porous fence). The reattachment point is at line $\mathrm{J}$ when $\phi=50 \%$ and line $\mathrm{H}$ when $\phi=$ $0 \%$. Large separation generated near the crest and leeward of the hill in the cases $\phi=$ $0 \%$ and $50 \%$ at lines D, E, F and G due to roughness. A thick internal boundary layer 
observed at lines $\mathrm{D}, \mathrm{E}$ and $\mathrm{F}$ in the cases $\phi=0 \%$ and $50 \%$ because of turbulent mixing generated by roughness. While, internal boundary layer at the same lines in case, $\phi=$ $100 \%$ is thin since there is no roughness.

Beside the mean velocity, it is of interest to know how turbulence might be modified as the flow goes over the hill. Turbulence structures behind two-dimensional hill are poorly understood. The turbulent velocity profiles also differ slightly. This corresponds to the differences in the mean velocity gradient. On the leeward of the hill, the turbulent velocity in longitudinal direction shows strong peaks around the turbulent mixing at lines F, G, H, I, J and $\mathrm{K}$ in the three cases. At some points, the turbulence intensity becomes higher than 0.3 , and the measurement with the X-probe should show corresponding errors.

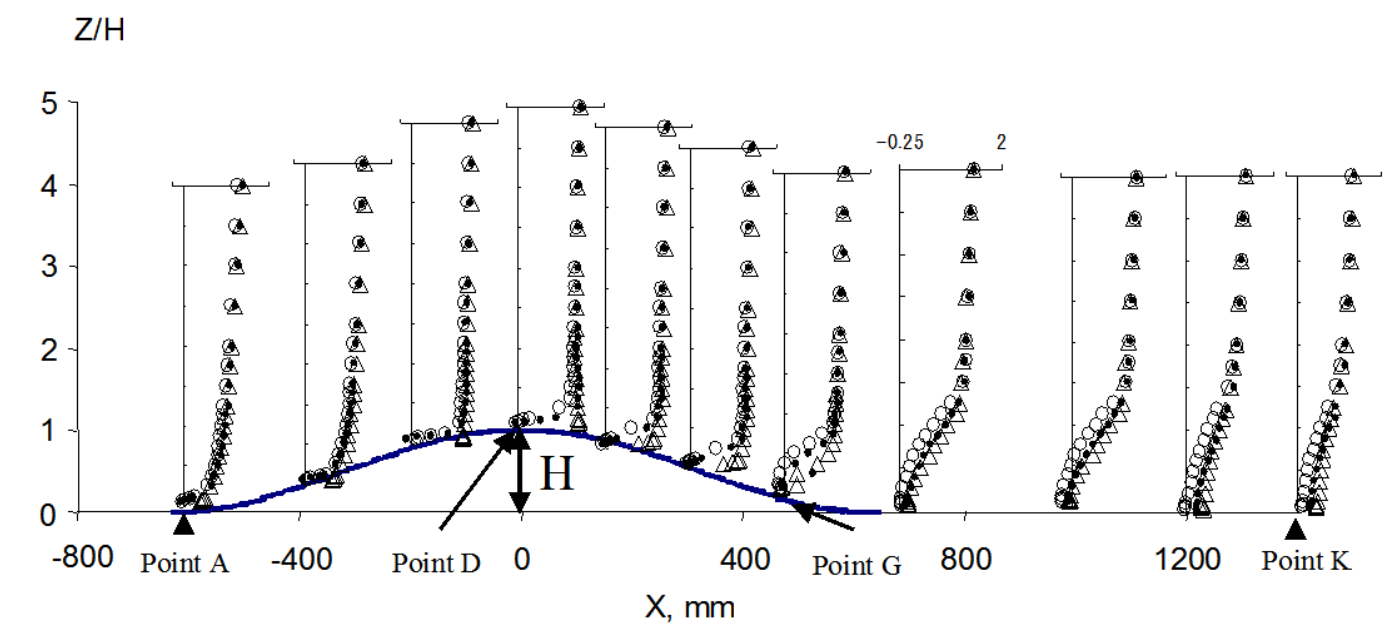

With fence ( $\phi=0)$, OWith fence ( $\phi=50 \%), \Delta$ With fence ( $\phi=100 \%)$

Fig. 7: Mean velocity component in the longitudinal direction $\left(U / \mathrm{U}_{H}\right)$.

\section{$\mathrm{Z} / \mathrm{H}$}

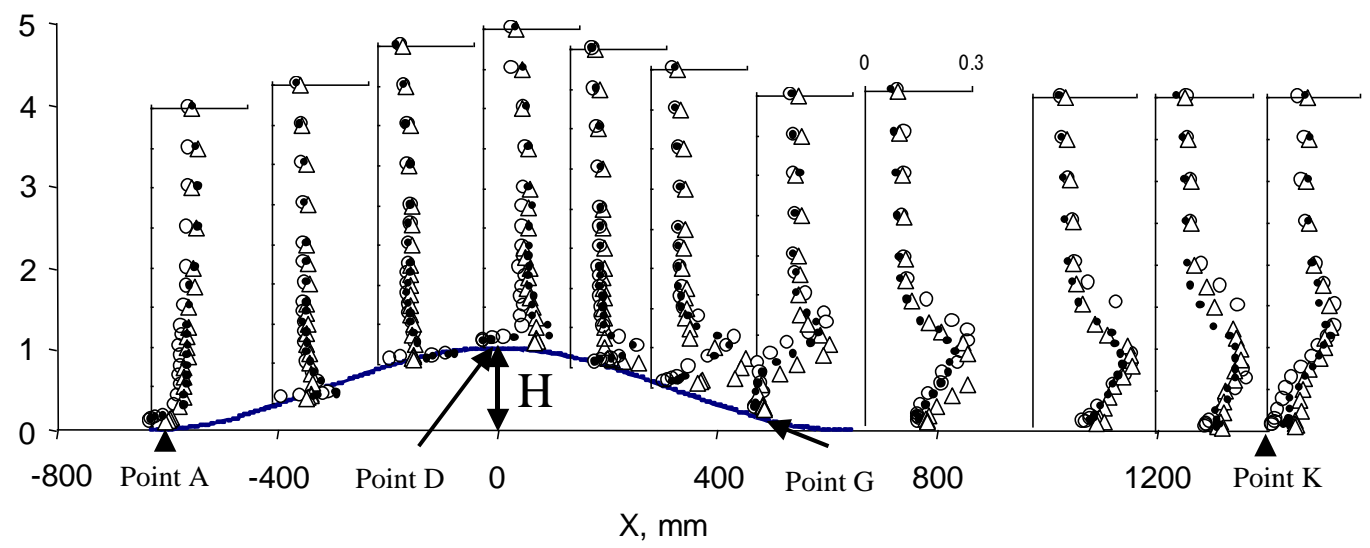

Fig. 8: Turbulent velocity component in the longitudinal direction $\left(\sqrt{\overline{u^{2}}} / U_{H}\right)$. 


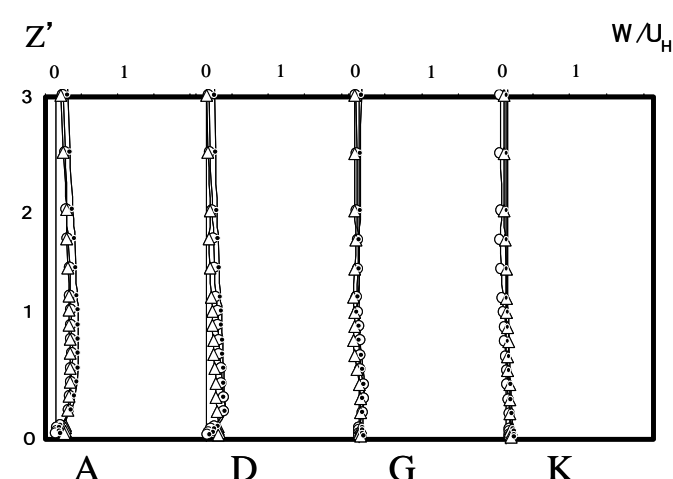

Fig. 9: Mean velocity component in the vertical direction $\left(\mathrm{W} / \mathrm{U}_{\mathrm{H}}\right)$.

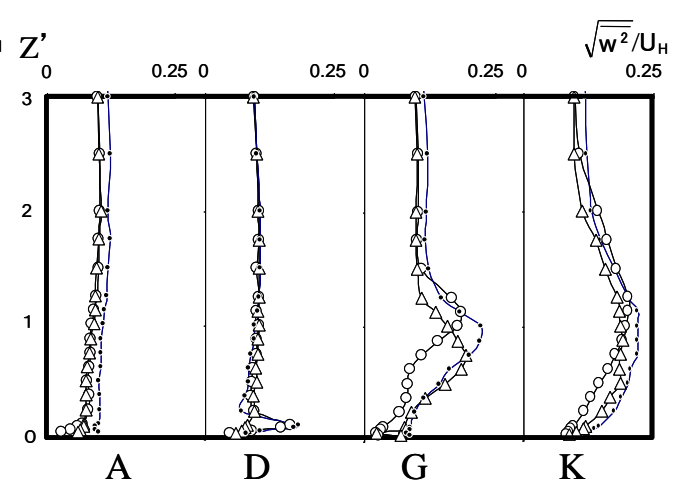

Fig. 10: Turbulent velocity component in the vertical direction $\left(\sqrt{\overline{w^{2}}} / \cup_{H}\right)$.

At the wake region behind the hill, the turbulent velocity when $\phi=50 \%$ is apparently higher than for the other cases. In contrast, the mean velocity becomes lower in the same region. The porous fences work as stronger wind breaks and weaken the wind velocity near the hill surface. This generates more turbulence than in the other cases.

The Reynolds stress and turbulent energy are shown in Figs. 12 and 13. On the crest hill, the absolute value of the Reynolds stress with solid fence, $\phi=0 \%$ at line D is larger than that two cases, $\phi=50 \%$ and $100 \%$ due to the large resistance on the solid surface. The eddy viscosity can be estimated from the mean velocity gradient and the Reynolds stress. Figure 14 shows the eddy viscosity estimated. The turbulence velocity of each component shows an almost uniform distribution on the windward ascent slope. The profiles of turbulent energy and Reynolds stress also show almost uniform distributions on the windward ascent slope. In the upper wake region, the turbulence energy is generated and gives an apparent peak.

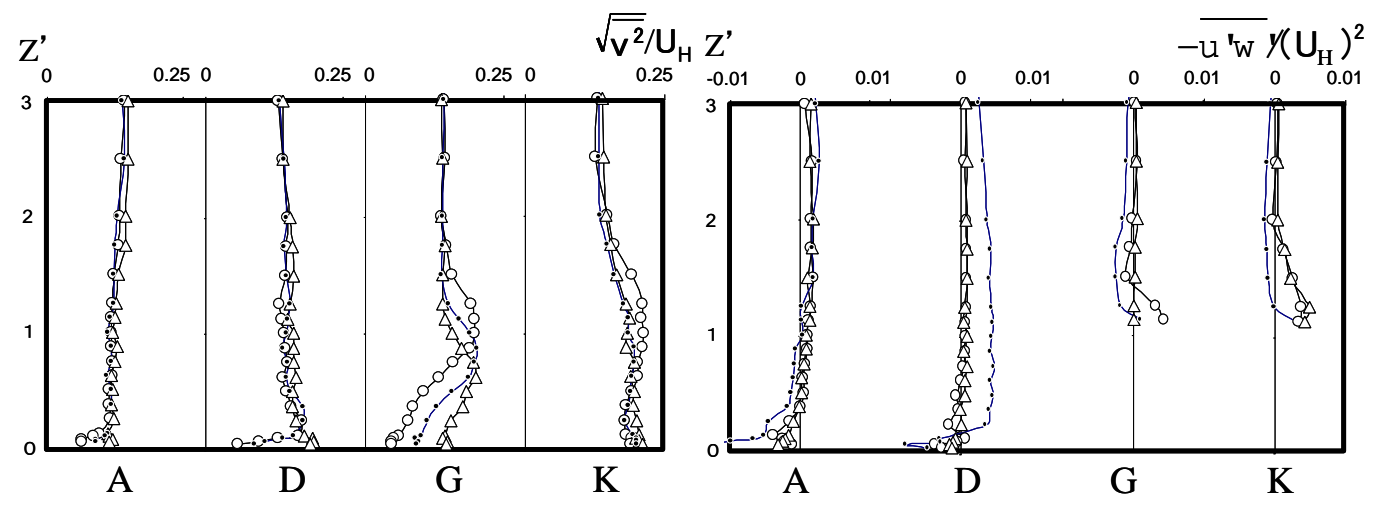

Fig. 11: Turbulent velocity component in the lateral direction.

Fig. 12: Reynolds stress $\left(\overline{-u^{\prime} w^{\prime}} / U_{H}^{2}\right)$. 


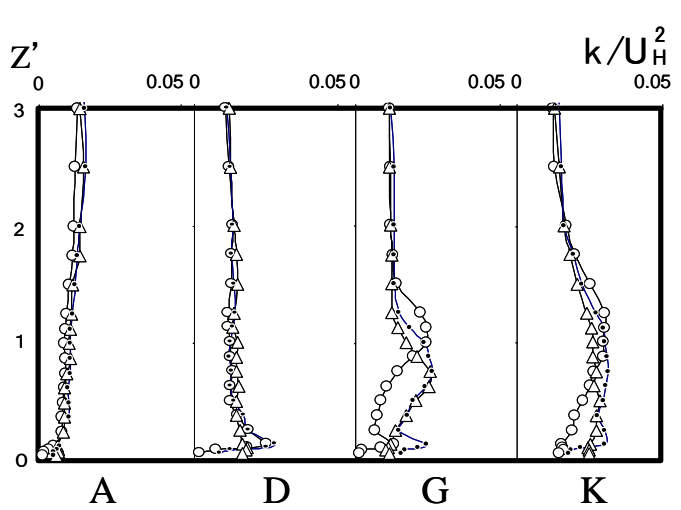

Fig. 13: Turbulent energy $\left(K / U_{H}^{2}\right)$.

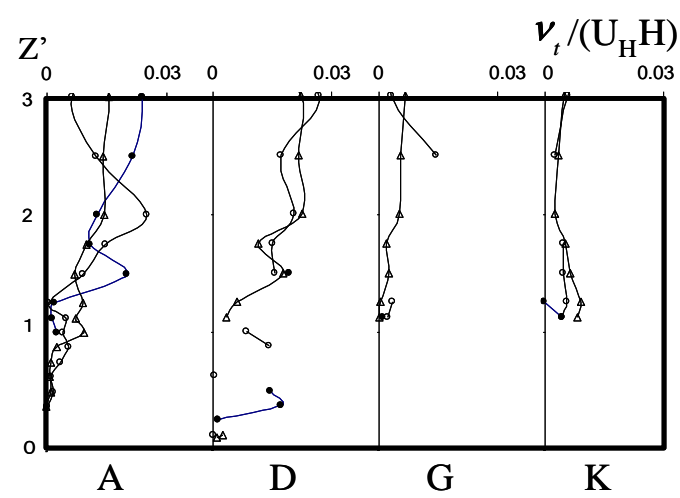

Fig. 14: Eddy viscosity $\left(v_{t} / U_{H} H\right)$.

\section{CONCLUSIONS}

The effect of surface roughness on the boundary layer flow over two-dimensional hill with different porous fences, $\phi=0,50$ and $100 \%$ have been investigated in the wind tunnel by using CTA system with split-fiber probe. The analysis results and discussion obtained be summarized as the following:

(1) The peak wind speed $\left(\mathrm{U} / \mathrm{U}_{\mathrm{H}}\right)$ above the hill surface is 1.37 when $\phi=100 \%, 1.33$ when $\phi=0 \%$, and 1.47 when $\phi=50 \%$,

(2) Large separation generated near the crest and leeward of the hill in the cases $\phi=$ $0 \%$ and $50 \%$ at lines D, E, F and G,

(3) A thick internal boundary layer observed at lines D, E and F in the cases $\phi=0 \%$ and $50 \%$ because of turbulent mixing generated by roughness,

(4) The reattachment point is $\mathrm{X} / \mathrm{H}=6$ when $\phi=50 \%$ and $\mathrm{X} / \mathrm{H}=3.5$ when $\phi=0 \%$,

(5) The turbulence velocity shows an almost uniform distribution across the windward ascent slope,

(6) The turbulence velocity becomes higher at the upper wake region behind the hill,

(7) The porous fences work as stronger wind breaks and weaken the wind velocity near the hill surface.

\section{REFERENCES}

[1] J.J. Finnigan, Air Flow Over Complex Terrain, Flow and Transport in The Natural Environment, Springer, Heidelberg, 1988, pp. 183-229.

[2] E.F. Bradley, An experimental study of the profile of wind speed, shear stress and turbulence at the crest of a large hill, Quart. J. Roy. Meteorol. Soc. 106 (1980) 101-124.

[3] J.J. Finnigan, M.R. Raupach, E.F. Bradley, G.K. Aldis, A wind tunnel study of turbulent flow over a twodimensional ridge, Boundary-Layer Meteorol. 50 (1990) 277-311.

[4] D.V. Neff, R.N. Meroney, Wind-tunnel modeling of hill and vegetation influence on wind power availability, J. Wind Eng. Indus. Aerodyn. 74-76 (1998) 335-343. 
[5] C.A. Miller, A.G. Davenport, Guidelines for the calculation of wind speed-ups in complex terrain, J. Wind Eng. Indus. Aerodyn. 74-76 (1998) 189-197.

[6] E.J. Plate, C.W. Lin, The velocity field downstream from a two-dimensional mode hill, Part I. Colorado State University, Fluid Dynamics and Diffusion Laboratory, Report No. CER65EJP14, 1965.

[7] J. Counihan, J.C.R. Hunt, P.S. Jackson, Wakes behind two-dimensional surface obstacles in turbulent boundary layer. J. fluid Mech. 64, 1974, pp. 529-563.

[8] A.H. Huber, W.H. Snyder, R.S. Thompson, R.E. Lawson, Stack placement in the lee of a mountain ridge, a wind tunnel study, EPA-600/4-76-047, Environmental Monitoring Series, U.S. Environmental Protection Agency, 45, 1976.

[9] I.P. Castro, Relaxing wakes behind surface - mounted obstacles in rough wall boundary layers, J. fluid Mech. 93, 1979, pp. 631-659.

[10] P.A. Taylor, P.J. Mason and E. F. Bradley: Boundary layer over low hills -A review, Boundary Layer Metrology vol. 39, 1987, pp.107-132.

[11] T.Ishihara and K.Hibi, An experimental study of turbulent boundary layers over steep hills, Proc of 15th National Sym. On Wind Eng., 1988, pp. 61-66.

[12] G.P. Almeida, D.F.G. Durao, M.V. Heitor, Wake flows behind two-dimensional model hills, Experimental Thermal \& Fluid Science, 7, 1993, pp. 87-101.

[13] P. Sierputowski, J. Ostrowski, and A. Cenedese, Experimental study of wind flow over the model of a valley, J. of Wind Engineering \& Industrial Aerodynamics 57, 1995, pp.127-136.

[14] Y. Meng and K. Hibi, Turbulent characteristics of flow field over a threedimensional steep hill, J. of Wind Eng. and Indus. Aerodyn., Vol. 73, 1997, pp.314 (in Japanese).

[15] T.Ishihara, K.Hibi and S. Oikawa: A wind tunnel study of turbulent flow over a three-dimensional steep hill, J. of Wind Eng. and Indus. Aerodyn., Vol.83, 1999, pp. 95-107.

[16] F.M. Fang, D.Y. Wang, On the flow around a vertical porous fence, J. of Wind Eng. and Indus. Aerodyn., Vol. 67 \& 68, 1997, pp. 415-424.

[17] Bao-shi Shiau, Measurements of turbulence characteristics for flow past porous windscreen, Journal of Wind Engineering and Industrial Aerodynamics, 74-76, 1998, pp. 521-530.

[18] Bao-shi Shiau, Experimental study of a turbulent boundary layer flow over a windbreak of semi-circular section, Journal of Wind Engineering and Industrial Aerodynamics, 84, 2000, pp. 247-256.

[19] A.R. Packwood, Flow through porous fences in thick boundary layers: comparisons between laboratory and numerical experiments, J. of Wind Eng. and Indus. Aerodyn., Vol. 88, 2000, pp. 75-90.

[20] J. Counihan, Adiabatic atmospheric boundary layers: a review and analysis of data from the period 1880-1972; Atmospheric Environment, Vol. 3, 1975, pp. 871-905.

[21] T. Boerner, H.J. Leutheusser, Calibration of split-fiber probe for use in bubbly two-phase flow, DISA info., No.29, 1984, pp. 10-13. 


\section{دراسة معملية لتأثيراتِ الأسطح الخثنة في طبقات الهواء المضطربه فوق الأبقاد تل ثنائي الأبعاد}

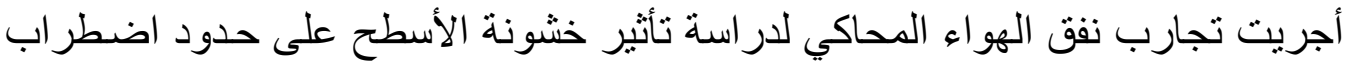

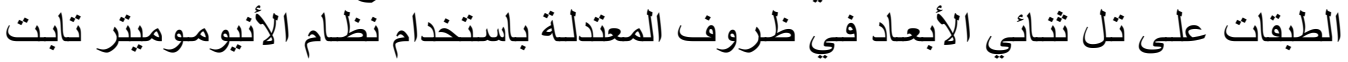

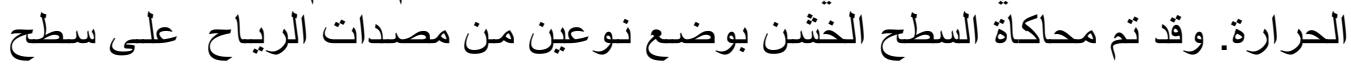

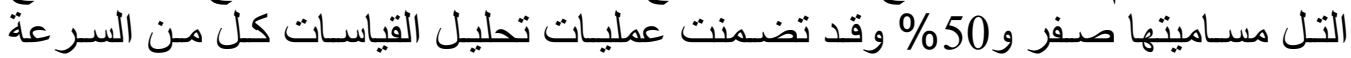

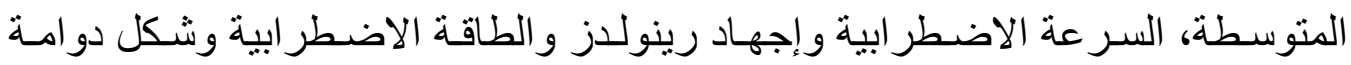

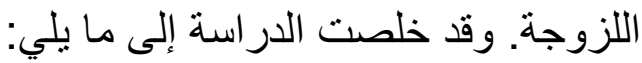

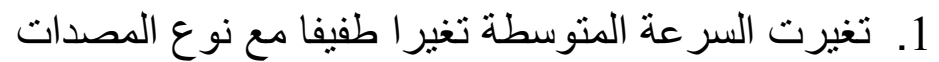

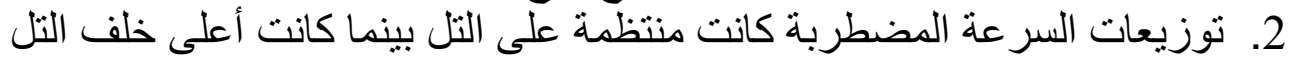

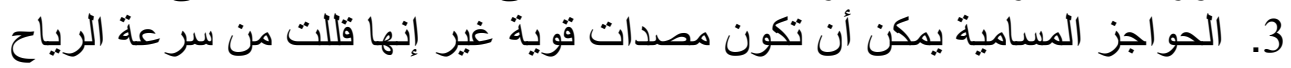

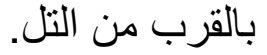

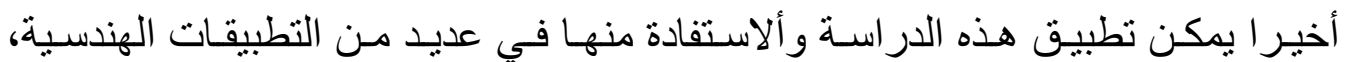

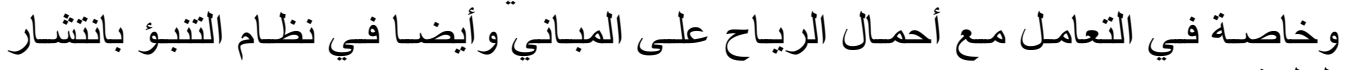

